ESJ Social Sciences

\title{
Moderating Effect of Organizational Capability on the Relationship Between Business Intelligence Capability and Performance Among Public Listed Firms in Kenya
}

\author{
Edward Buhasho \\ Director, Finance and Administration, \\ Blue River Technology Solutions, Nairobi, Kenya \\ Agnes Wausi \\ Professor, School of Computing and Informatics, \\ University of Nairobi, Kenya \\ James Njihia \\ Professor, School of Business, University of Nairobi, Kenya
}

Doi:10.19044/esj.2021.v17n1p335

Submitted: 23 November 2020

Accepted: 08 January 2021

Published: 31 January 2021
Copyright 2021 Author(s)

Under Creative Commons BY-NC-ND

4.0 OPEN ACCESS

Cite As:

Buhasho E., Wausi A. \& Njihia J. (2021). Moderating Effect of Organizational Capability on the Relationship Between Business Intelligence Capability and Performance Among Public Listed Firms in Kenya. European Scientific Journal, ESJ, 17(1), 335.

https://doi.org/10.19044/esj.2021.v17n1p335

\section{Abstract}

Business Intelligence remains a primary focus in many organisations and it naturally attracts significant investment. Existing literature is nebulous and fragmented on the real impact and how well the insights induced by this technology have been transformed into successful business learning. Consequently, this paper focuses on determining the influence of organizational capabilities on the relationship between Business Intelligence capability and firm performance. The study employed interdisciplinary theories to realize the research objective, namely Information Systems Capability theory and Organizational Learning theory. In addition, the study was conducted using mixed methods research methodology and a crosssectional approach. The study used structural equations modeling technique (Partial Least Squares approach- SEM-PLS) to analyse quantitative data and validate the developed research model. Thematic analysis aided by Atlas.ti version 8 software was applied to analyse qualitative data. Findings of quantitative and qualitative strands of the study were triangulated at the data 
analysis stage based on convergence model. Results revealed that organizational capability has a positive and significant moderating impact. The findings provide fresh enlightenment into current Business Intelligence literature and opportunities for future research with implications for management, policy makers, and academia.

Keywords: Business intelligence, firm performance, organizational capability

\section{Introduction}

Business Intelligence (BI) is a rapidly growing innovation occasioned by prevalent business environment globally, i.e., it is evolving, dynamic, and is characterized by huge amounts of data originating from social networks and mobile communications, in addition to traditional databases. BI focuses on remodeling raw data into utilizable, useful, and actionable (knowledge) facts. Additional knowledge contributes to an organization's success by facilitating better decisions, hence, impacting performance (LaValle et al., 2011). Investment by Michigan State University in BI generated annual savings of $\$ 34,434$ and $55 \%$ return by eliminating manual data analysis, therewith allowing staff to concentrate on critical activities (Durcevic, 2018). A survey of more than 400 experts in Information and Communication Technology (ICT) collected from 93 countries suggested that BI is a core investment in companies (Arefin et al., 2015). Global BI investment was anticipated to be valued at $\$ 22.8$ billion by the end of 2020 (Moore, 2017).

ICT expenditure in Kenya reflects an upward trajectory, for instance, from $\$ 2.28$ billion in 2016 to $\$ 3.45$ billion in 2017 (Kenya National Bureau of Statistics, 2018). In comparison, however, corporate institutions' performance, especially publicly listed companies, has declined in the recent past (Kinuthia, 2018). Recent profit warnings by the listed companies have resulted in a major decline in share prices, consequently, shrinking investment value of shareholders. Publicly listed firms play a crucial role in economic development. Hence, solid performance in these firms is extremely important. Data is regarded as a resource and can be exploited through the use of BI systems to enhance profitability and competitiveness (Williams, 2016), thereby reshaping the declining trend of these firms. In addition, due to shorter product life cycles, changes in social norms and demographic patterns, these firms operate in a constantly changing operating environment (Audzeyeva \& Hudson, 2016). The ability to detect and respond to such variations should therefore be developed by exploiting BI capabilities. The impact of BI is realized through improved decision-making based on facts, business process improvement, innovation, and environmental changes (LaValle et al., 2011; Brynjolfsson et al., 2011; Audzeyeva \& Hudson, 2016). Moreover, Watson 
and Wixom (2007) concluded that with correct capabilities, BI can assist an organization to forecast a shift in product demand or spot an increase in the market share of a competitor's product and react rapidly by introducing a competing product.

Empirical results on BI impact is fragmented (Audzeyeva \& Hudson, 2016) and lack an overall framework incorporating moderating variables (Trieu, 2017), in spite of ongoing substantial investment in BI solutions. The positive impact of BI on firm performance has indeed been reported (Brynjolfsson et al., 2011; Fink et al., 2017). Investment by Michigan State University in BI generated annual savings of $\$ 0.34$ million and investment return of 55\% (Durcevic, 2018). However, other studies, for example, Chae et al. (2014), have underscored the negative impact of IT on performance. Similarly, Carr's (2003) study highlighted the non-significant effect of IT investment. A survey conducted by Henshen (2008) on BI impact reported a $19 \%$ success rate on business performance.

Empirical studies carried out by other researchers on the role of organizational capabilities revealed various shortcomings. For example, Melville et al. (2011) posit that IT performance value research is confronted with a variety of constructs and corresponding factors, and there is no consensus on approaches to modeling these constructs. Mithas et al. (2011) conducted research on how information capability impact performance. The study confirmed the impact of BI in developing organizational capabilities and this by extension influences performance through customer, process, and management capabilities. The findings indicate that the link between BI and performance is moderated by organizational capability. However, further research by Yogev et al. (2013) on how BI generates value has shown that value is achieved by enhancing both operational and strategic business processes. Xu and Kim (2014) argued that the impact on performance is driven by the development of dynamic capabilities that facilitate sense and response strategies to environmental changes. Aydiner et al. (2019 has recently echoed the need to take further steps to open the black box linking IS capabilities and performance by using appropriate mediating/moderating variables. Božič and Dimovski (2019) concluded that the process of converting BI's insights into viable business learning remains vague and calls for further studies to investigate this complex phenomenon. Hence, the objective of this study was to examine the moderating effect of oorganizational capabilities based on the relationship between BI capability and firm performance.

\section{Literature Review}

2.1 Theories Underpinning the Study

The study views BI impact through two lenses; Information Systems (IS) capability theory and Organizational Learning Theory. IS capability 
theory provides a mechanism through which an organization can continually obtain value by adopting technology (Peppard \& Ward, 2004). This enables an organization to convert data into knowledge that has business value; consequently, it enhances its long run ability to adjust to changes (William, 2016). Hence, the theory advances the premise of BI capability adopted in the current study. OLT Theory leverages on the progress of learning arising from the firm's past mistakes over a period of time. For learning to succeed, organizational leaders must make a concerted effort to change tact in response to changing circumstances, connect action to an outcome, and measure the outcome (Larsen \& Eargle, 2015). Notable contributors to this theory are Argrys and Schon (1978) and Fiol and Lyles (1985). Gupta and George (2016) stressed that businesses, with high inclination towards learning, have stocks of knowledge that can be used to build huge data capability. Therefore, organizational learning is a valuable theoretical lens for understanding the impact of BI (Fink et al., 2017).

\subsection{BI Capability}

BI capability concept emanates from IT capabilities (Kulkarni et al., 2017), which scholars have studied extensively in the information systems (IS) literature, for example, Bharadwaj (2000). According to Bharadwaj (2000), IT capability is an organizational capability used to organize and deploy IT-based resources together with other available resources to yield a competitive advantage. Thus, beyond technology, firms rely on other resources to build unique capabilities that are difficult to imitate (Olszak, 2014). In reference to IS capability theory, BI capability is associated with vital functionalities that assist firms to generate and leverage value through BI tools continuously (Peppard \& Ward, 2014; Olszak, 2014; Isik et al., 2013). Isık et al. (2013) enhanced this concept by investigating the role of BI capabilities from an organizational and technical point of view. They established and validated nine capabilities incorporated in this study. In addition, literature suggests that human capital is a vital resource (Stevens, 2010; Bharadwaj, 2000). Hence, human capital dimension was included under BI capability.

\subsection{Firm Performance}

Performance is a construct that has multiple dimensions. It hinges on the use of economic indicators of performance such as market share, growth in revenue, and profitability (Melville et al., 2004). It also includes nonfinancial indicators such as product quality and customer satisfaction (Trieu, 2017). To assess performance, Kaplan and Norton (1996) proposed Balanced Score Card (BSC) framework composed of four perspectives namely customer, internal process, organization learning, growth, and financial. This 
study, however, embraced the Malcom Baldrige National Quality Award (MBNQA) framework, which explicitly tests IT-driven information flows (Mithas et al., 2011). In addition, the dimensions used met the criteria by Wade and Hulland (2004) for selecting appropriate dependent variables to be used when evaluating benefits accruing from IT that should reflect trends and competitiveness. The dimensions comprises human resource, customer-focus, financial, and organizational effectiveness to evaluate the performance impact of BI.

\subsection{Organizational Capability}

Organizational capability relates to the firm ability to utilize its competencies to effectively respond to its environment (Kangas, 1999). Competence, according to McGrath, MacMillan and Venkataraman (1995), emerges from an objective blend of specific resources that facilitates the firm to carry out a given task. Top management must therefore accumulate, classify, develop, and use the resources of the organization efficiently over time. Organizational capability was further conceptualized by Mithas et al. (2011) to encompass process management capability, customer management capability, and performance management capability. Consumer management capability enables an organization to use the voice of the customer to collect market intelligence and identify opportunities for business. Effective BI capabilities allow the organization to obtain customer information and propagate to respective stakeholders in the organization. Shared information between customer service units and IT units affects the capacity of the firm to obtain market intelligence (Ray et al., 2005) for strategic realignment. Process management capability is the capacity to create a procedure with effective scope and wealth for steering the firm's activities. McGrath et al. (1995) observed that the competitive advantage, to some extent, is related to processes at work within the organization that result in a reliable and repetitious attainment of desired output. Therefore, an individual organization undertakes sets of actions in order to realize its strategic objectives, hence, creating numerous avenues for the application of IT to streamline business operations (Melville et al., 2004). BI capability permits a quicker and more responsive redesign and configuration of processes in reaction to shifts in the business environment, which in turn enhances organizational performance.

Performance management refers to the capacity to create requisite monitoring and check systems to examine business performance. It permits firms to align strategic and operational goals with business operations to fully sustain performance via better and informed decision-making and action (Bogdana et al., 2009). It encompasses the choice of suitable measurement methods, data collection, and data analysis. An effective performance management system can make it possible for a firm to identify unfavourable 
variations, ascertain sources of variation, and implement new strategies geared towards identifying a viable solution (Mithas et al., 2011).

\subsection{Business Intelligence Capability, Organizational and Firm Performance}

Prior research by Kohli and Grover (2008) posit that information management capability that is driven by IT leads to enhanced business capabilities, thereby affecting firm performance positively. Information management capability is a subset of BI capability (Kulkarni et al., 2017). Therefore, Mithas et al. (2011) propounded a model involving two stages, information management capability as primary construct and organization capabilities made of higher-order capabilities (process management, performance management and customer management capabilities) as an intermediary between performance and information capability. The results based on chronicled data set, from a conglomerate outfit, confirmed that organizational capability has an impact on the relationship between information capability and firm performance (Mithas et al., 2011). However, the findings from this research cannot be generalized to firms globally because the data set was limited to firms within the group.

Empirical research conducted by Ray et al. (2005) in North America revealed that shared information enabled by IT notably affects the capacity of the firm to obtain more customer intelligence and associated business processes with a final impact on business performance. The research setting was on a specific insurance industry with an exceptional spotlight on the customer process. Thus, the generality of the study is limited. Likewise, in their survey-based study, Elbashir et al. (2008) discovered BI conveys benefits through improved business processes (business partner relations, inside procedure proficiency, and client insight benefits). A survey study by Kim et al. (2011) in South Korea confirmed that IT capability influence process oriented dynamic capability and the subsequent impact on firm performance. It enables management to either enhance, adapt, or restructure business process better than other competing firms in terms of consolidating business activities and cost containment. However, the study did not incorporate other factors (customer and performance management capability). In line with the theoretical propositions in the IS capability theory, Mithas et al. (2011) posit that BI capabilities play a critical role in developing organizational capabilities. These capabilities in turn favourably influence customer, financial, human resources, and organizational effectiveness (measures of firm performance). This study seeks to contribute to the ongoing debate by focusing on the mediating role of organizational capability. It is hypothesized that:

$\boldsymbol{H}_{01}$ : Organizational capability has no effect on the relationship between BI capability and firm's performance. 
Relationship between the variables under study is presented in Figure 1 below.

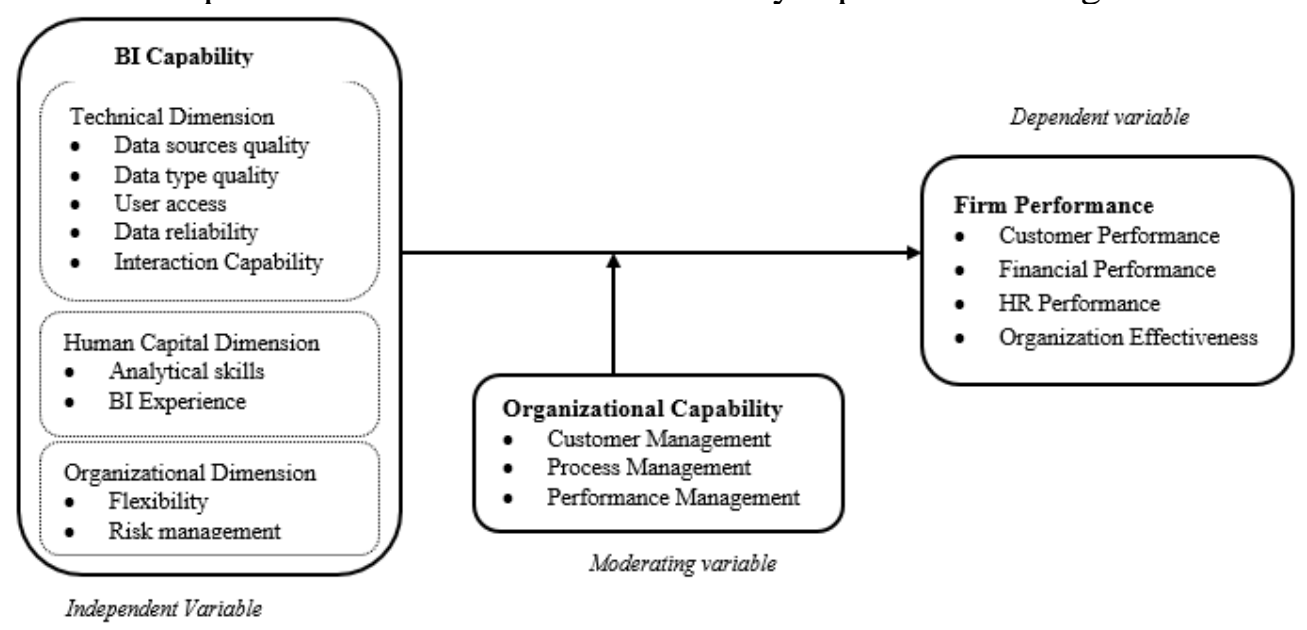

Figure 1. Conceptual Model

\section{Methodology}

\subsection{Research Design and Population}

The study adopted cross-sectional mixed method research design in which elements of qualitative and quantitative approaches were combined (Johnson et al., 2007). The rationale for adopting this design includes the ability to integrate the strength of different methods, provides an in-depth insight into phenomena that are enigmatic while using quantitative or qualitative methods, and address issues of research involving a real-life understanding of context, multi-dimensional views, and cultural influence (Johnson et al., 2007). The study's target population was public listed firms at the Nairobi Securities Exchange (NSE) as at $31^{\text {st }}$ of December 2018. All 64 listed firms were contacted to participate in the study.

\subsection{Data Collection and Analysis}

Data were obtained via a structured questionnaire. In designing the questionnaire, a five-point Likert scale with items ranging from ' $1=$ not at all' to '5 = very large degree' were selected. Data was collected from staff in managerial positions. This is because they are regarded as key informants with knowledge about the research topic (Kim et al., 2011). Questionnaires totaling 64 were issued using drop-and-pick methods. To analyse the data, the researcher used the Structural Equation Modelling technique (SEM) for quantitative strand of the study. SEM was employed to evaluate the measurement model, to confirm the fit of the model, and to verify the convergent and discriminant validity of the constructs. SEM also enables the modeling and estimation of complicated relationship patterns and test hypotheses simultaneously in a single run (Hair et al., 2017). Specifically, 
PLS-SEM was adopted to assess the hypothesis using SmartPLS version 3.0. PLS-SEM is a suitable tool to explain changes in key constructs caused by other constructs, including the ability to function with a small sample size (Hair et al., 2014). Thematic analysis technique, complemented by Atlas.ti version 8 software, was employed to analyse qualitative data.

\section{4. $\quad$ Findings}

\subsection{Assessment of the Measurement Models}

The reflective measurement model was assessed by item reliability, internal consistency reliability, discriminant validity, and convergent validity. To achieve item reliability, all indicators loadings were evaluated. Chin (1998) specified that the loading of indicators should be at least 0.60 and preferably 0.70 or greater. Hair et al. (2014) argued that indicators with outer loads between 0.40 and 0.70 should only be considered for removal from the scale if removal of the indicator leads to improved composite reliability. Consequently, any indicator with loads below 0.60 was dropped one at a time until only those with loads above 0.60 remained.

Cronbach's alpha is the standard measure for internal consistency, which presents a reliability estimate based on the inter-correlations of observed variables. Hair et al. (2017), however, recommended the use of composite reliability because Cronbach's alpha is sensitive to the number of items in the scale and often underestimates the reliability of internal consistency. The authors specified that composite reliability values of 0.60 to 0.70 is appropriate in exploratory research. Results for the composite reliability were as follows; BI capability 0.926 , organizational capabilities 0.906 , and financial performance 0.880 . These surpassed the minimum criteria of 0.7 as shown in Table 1 .

Table 1. Construct Internal Consistency Reliability

\begin{tabular}{lrr}
\hline Construct & Cronbach's Alpha & Composite Reliability \\
\hline BI Capability (BC) & 0.914 & 0.926 \\
Financial Performance (FP) & 0.843 & 0.880 \\
Organizational Capabilities (OC) & 0.877 & 0.906 \\
\hline
\end{tabular}

Convergent validity is the extent to which observed variables are highly correlated with a particular construct. To verify convergent validity, Average Variance Extracted (AVE) of each latent variable was assessed. Validity is confirmed when AVE values are greater than the acceptable threshold of 0.5 (Hair et al., 2017). The AVE values for the current study are listed in Table 2. The AVE value for all constructs ranged from 0.507 to 0.592 , which is above the acceptable value of 0.5 . Hence, the model has satisfactory convergent validity. 
Table 2. Average Variance Extracted (AVE)

\begin{tabular}{lc} 
Construct & Average Variance Extracted (AVE) \\
BI Capability & 0.513 \\
Firm performance & 0.514 \\
Organizational capabilities & 0.582 \\
\hline
\end{tabular}

Discriminant validity is the extent to which the construct is empirically distinct from other constructs (Hair et al., 2014). However, recent studies have demonstrated that cross-load approach and the Fornell-Larcker criterion do not reliably detect discriminating validity (Henseler et al., 2015; Hair et al., 2017). Henseler et al. (2015) suggested an alternative technique to evaluate discriminant validity based on the multitrait-multimethod matrix known as the heterotrait-monotrait correlation ratio (HTMT). Discriminatory validity is established when HTMT value is below 0.90 (Garson 2016; Henseler et al., 2015). As indicated in Table 3, discriminating validity for all pairs of latent constructs was confirmed.

Table 3. Heterotrait Monotrait Ratio

\begin{tabular}{llll}
\hline & BC & OC & FP \\
\hline BC & & & \\
OC & 0.852 & & \\
FP & 0.478 & 0.433 & \\
\hline
\end{tabular}

\subsection{Structural Model Evaluation}

Assessment of the hypothesized relationship within the inner model commences after verification of reliability and validity measurement model (Hair et al., 2014). Hair et al. (2017) stipulated the main criteria for assessing PLS-SEM structural model and include significance of path coefficients, the level of the $\mathrm{R}^{2}$ values, the $\mathrm{f}^{2}$ effect size, the predictive relevance $\mathrm{Q}^{2}$, and the $\mathrm{q}^{2}$ effect size are presented below. However, the model was first evaluated for collinearity issues by applying variance inflation factor (VIF) mooted by Hair et al. (2017). A well-fitted model without multicollinearity should have less than 5.0 VIF coefficients (Garson, 2016). For predictor constructs, all VIF values (BI capability was 2.916 and organizational capabilities 2.904) were below 5 , indicating lack of multicollinearity.

Predictive accuracy of the model is measured by $\mathrm{R}^{2}$ and is computed as the squared correlation between the actual and expected values of a particular endogenous construct. The measure generates insights into the predictive power of a model. $\mathrm{R}^{2}$ values of $0.75,0.50$ or 0.25 are categorized as significant, moderate or weak respectively (Hair et al., 2017; Garson, 2016). Predictive power on firm performance was 0.458 . This implies that the model can explain 45.8 percent changes in firm performance. Cohen's $\mathrm{f}^{2}$ metric tests the strength of the independent variable in relation to $\mathrm{R}^{2}$. Based on the value 
extracted, BI capability has large predictive power on complementary resources $\left(\mathrm{f}^{2}\right.$ value of 1.242). Complementary resources have medium predictive power on performance ( $\mathrm{f}^{2}$ value of 0.082 ).

Stone-Geisser's $\mathrm{Q}^{2}$ is a measure used to test the predictive relevance of the inner model through a blindfolding process. Blindfolding is a sample reuse method that systematically removes data points and gives an estimate of the initial values. Chin (1998) stated that $\mathrm{Q}^{2}$ values above 0 imply that the model has a predictive relevance to a specified endogenous variable. Values below 0 suggest a lack of predictive significance. The study yielded a firm performance value of 0.209 . Thus, the model indicates a comparatively high degree of predictive relevance for endogenous variable. The $\mathrm{q}^{2}$ effect size is a measure used to assess the relative predictive relevance to the dependent variable of a given independent (exogenous) variable. According to Hair et al. (2017), values of $0.02,0.15$, and 0.35 , respectively imply that an independent variable has a small, medium or large predictive relevance on endogenous construct. The $\mathrm{q} 2$ effect size for BI capability and organizational capability was 0.01 and 0.02 , presented in Table 3 . The findings indicate that the exclusion of organizational capability has a small effect on the predictive relevance of the current model.

Table 3. Cross-validated redundancy $\left(\mathrm{Q}^{2}\right)$ and $\mathrm{q}^{2}$ Effect size

\begin{tabular}{lcccc}
\hline & SSO & SSE & $\begin{array}{c}\mathrm{Q}^{2}(=1- \\
\text { SSE/SSO })\end{array}$ & q2 effect size \\
\hline Firm performance & 385 & 304.4 & 0.209 & \\
Omission of BI Capability (BC) & & & & 0.01 \\
Omission of Organizational capabilities (OC) & & & 0.02 \\
\hline
\end{tabular}

\subsection{Hypothesis Testing}

The two-stage method of PLS algorithm to analyse moderation effect was applied to test the hypothesis (Hair et al., 2017). The first stage consisted of examining the moderating impact of orgnizational capabilities (OC) on the relationship between $\mathrm{BI}$ capacity (BC) and firm performance (FP). The second stage was to evaluate the direct effect between $\mathrm{OC}$ and firm performance to collaborate with findings in the first stage. To carry out moderation analysis in SmartPLS, interaction term labelled moderating effect 1 was added to the model as shown in Figure 2. 


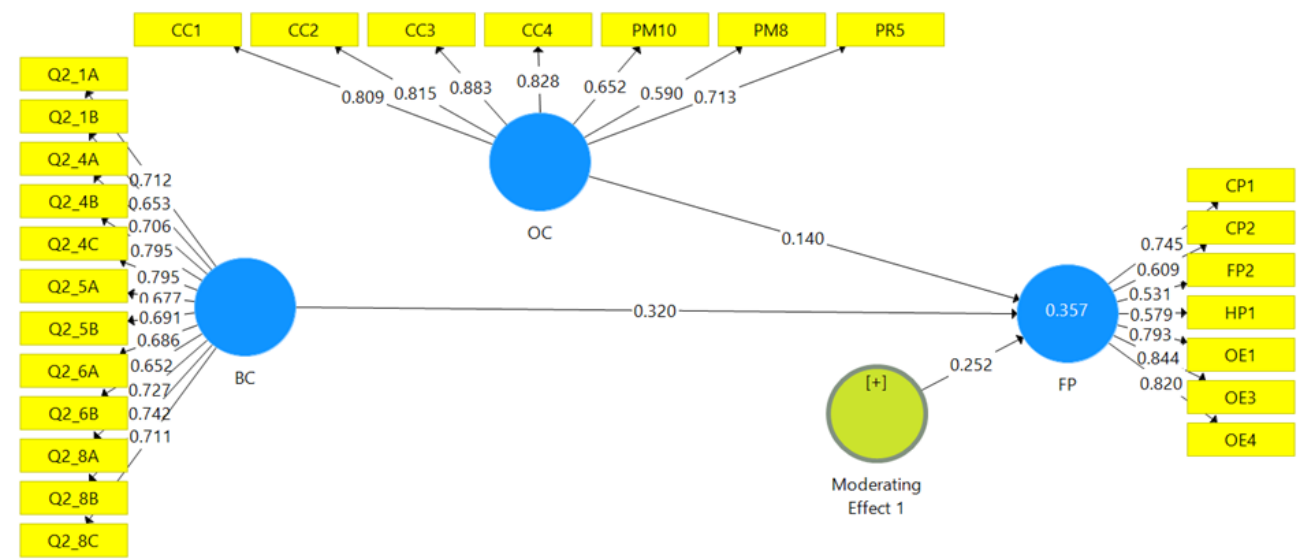

Figure 2. Moderation Effect of CR on the relationship between FP and BC

As indicated, interaction term has a positive impact of 0.252 on firm performance (FP). The results in Figure 2 show that the relation between BI capabilities (BC) on FP is 0.320 . It implies that when organizational capability $(\mathrm{OC})$ is increased by one standard deviation unit, the relationship between $\mathrm{BC}$ and FB is increased by the size of the interaction term $(0.320+0.252=0.572)$. Conversely, if $\mathrm{OC}$ is reduced by one standard deviation unit, the relationship between BC and FB becomes 0.068 (0.320 less 0.252). The following simple slope plot depicts the two-way interaction effect.

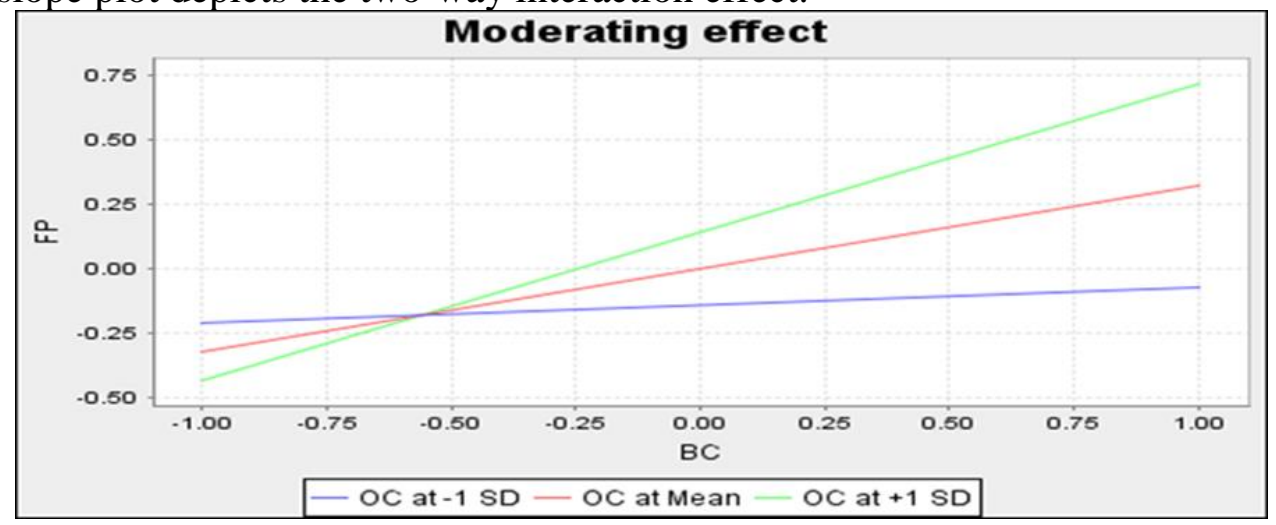

Figure 3. Simple slope plot on Moderating effect

The three lines shown in Figure 3 reflect the BC (x-axis) to FP (y-axis) relationship. The middle line reflects the relationship for a mean level effect of the moderating variable OC. The other two lines portray the association between $\mathrm{BC}$ and FP for average value of OC plus one standard deviation unit and mean value of $\mathrm{OC}$ less one standard deviation unit.

The moderation test also involved bootstrapping to test for significance and the results were as follows: $\beta=0.252, P$-value $=0.021$, tvalue $=2,302$, and $R^{2}=0.357$. The finding for the moderated relationship of 
the effect size $\left(\mathrm{f}^{2}\right)$ is medium at 0.145 . The highlighted findings empirically show that at the significance level of $\mathrm{P}<0.05$ and $\mathrm{t}>1.96$, the moderating impact of organizational capabilities is positive and statistically significant. The direct effect of organizational capability on firm performance results were as follows: $\beta=0.445$, $\mathrm{t}$-value $=3.590$, and $P$-value $=0.000$. The predictive power $(\mathrm{R} 2)$ results were: $\mathrm{R} 2=0.198$ and $\mathrm{f} 2=0.248$. Therefore, this indicates a positive and statistically significant relationship between organizational capability resources and firm performance. The f2 effect size value of 0.23 implies that organizational capability in this relationship has a medium proportion of predictive power. Therefore, the hypothesis is rejected.

\section{Qualitative Data Analysis}

Thematic analysis technique was adopted to analyse qualitative data. All the interviews were recorded and later transcribed. The interview sessions were conducted by the researcher to ensure consistency in the interview process and feedback interpretation. Before commencing analysis, the researcher read through the transcribed data while listening to recorded interviews, providing an opportunity to correct transcription errors. The edited version was then uploaded to Atlas.ti software. Summary findings are depicted in Table 4. BI output support management of customer level agreement and forecast change in customer preferences. In addition, it is used to manage business processes and triggers process changes. Furthermore, it enhances business performance by comparing actuals to target and conduct trend analysis, thus enabling management to take corrective action to avert crisis.

Table 4. Organizational Management Capability Key Findings

\begin{tabular}{|l|l|c|c|}
\hline Dimension & Description & Findings \\
\hline $\begin{array}{l}\text { Organizational } \\
\text { capability }\end{array}$ & $\begin{array}{l}\text { The variable } \\
\text { entails customer } \\
\text { management, } \\
\text { process } \\
\text { management, and } \\
\text { performance } \\
\text { management } \\
\text { capabilities. }\end{array}$ & $\begin{array}{l}\text { Output from BI is used to manage customer } \\
\text { expectation, predict preference, and manage service } \\
\text { level agreements. }\end{array}$ \\
& $\begin{array}{l}\text { BI is used to monitor processes in the organization. } \\
\end{array}$ & $\begin{array}{l}\text { BI can trigger a change in the organization process. } \\
\text { organization. It is used to evaluate performance in } \\
\text { order to flag corrective action to mitigate crisis. }\end{array}$ \\
\end{tabular}

\section{Discussion of Findings}

The findings empirically confirm that the impact of organizational capability is positive and statistically significant. Likewise, in their surveybased study, Elbashir et al. (2008) discovered that BI conveys benefits through improved business processes. Empirical research by Ray et al. (2005) concluded that shared information facilitated by IT has a major impact on the company's ability to gain more customer insights and related business 
processes with a final impact on business performance. A study conducted by Mithas et al. (2011) concluded that BI capability plays a critical role in developing organizational capabilities. In turn, these capabilities favourably influence customer, financial, human resources, and organizational effectiveness (measures of firm performance). Moreover, the results showed that BI capability has the greatest impact on performance management, followed by process management and then customer management.

Qualitative strand of the study confirmed the role of organizational capability in enhancing performance benefits from BI. Participants demonstrated that BI is a one-stop shop for all stakeholders in the organization. It is applied in performance management by flagging out corrective action to mitigate crises. It is also used to monitor critical processes and can trigger a change to improve efficiency. BI enhances customer management capability with final impact on performance. This application enables organizations to obtain intelligent information relating to customers by enabling deeper analysis of data collected from multiple sources such as e-mail, the internet, mobile, and twitter. Customer profiles are analysed to define expectations, predict preference, and manage service level agreements.

\section{Conclusions and Contributions of the Study}

The study was structured with a specific objective of investigating the effect of organizational capabilities in mitigating some of the limitations identified in the published literature. Hence, the outcome of this study exhibited a positive moderating effect of organizational capabilities on the relationship between BI capabilities and firm performance for publicly listed companies. To further improve declining performance, firms should deliberately develop higher capabilities (customer, process and performance capability) based on the output from BI. Moreover, the study has contributed to OLT by availing empirical proof relating to the indirect role of organization learning in enhancing firm performance. For organizational capability to be effective, learning must take place. For example, in performance management, BI provides feedback on revenue by flagging variance on dashboards. In the event of adverse variance, management learns by drilling down to the root causes. Improvement plan is developed and implemented swiftly, with results tracked and submitted to stakeholders for review. Learning process begins with individuals before the acquired knowledge is entrenched within the organisation.

This study provides practical insights to the managers and leaders of publicly listed companies in Kenya by validating the moderating effect of organization capabilities. Management of listed companies will be guided by the study to ensure BI is applied in customer management to monitor changes in expectations, trends, and service level agreements. Furthermore, effective 
performance management supported by BI will enable management to detect unfavourable variations, ascertain sources of variation, and implement appropriate strategies to correct the variation in business. BI capability permits a quicker and more responsive redesign and configuration of processes in reaction to shifts in business environment, which in turn enhances organizational performance. The finding of this research is also crucial for policy makers to formulate and improve the current policy frameworks for the listed companies, government, and other institutions. The study offers empirical evidence that BI capability and organizational capability are critical in enhancing firm performance. Hence, the study accentuates the need for investment in BI solutions.

\section{Study's Limitations and Suggestions for Further Research}

While this study has provided valuable insights, it also has some specific limitations. First, the findings of the study centred on cross-sectional data. BI support is of a long-term nature and cannot fully achieve its benefits over a short time span. In future research, the longitudinal research design could be used to enhance the reliability of performance data. Second, data was obtained from individual managers in various departments, e.g., ICT and finance managers. While it is anticipated that respondents will offer unbiased answers, because of variations in their role and profession, they could have contributed to differing perceptions as to how items in questionnaires were addressed. Typically, organizations use different BI systems to analyse, present, share, and create insights for decision making. It is not clear if the impact varies depending on which BI system is in use. Hence, further studies are required to evaluate the impact from the same vendor.

\section{References:}

1. Arefin, M., Hoque, M., \& Bao, Y. (2015). The impact of Business Intelligence on organization's effectiveness: an empirical study. Journal of Information Technology, 17(3), 263-285. https://doi:10.1108/jsit-09-2014-0067

2. Argyris, C., \& Schön, D. A. (1978). Organizational learning: A theory of action perspective. Reading, MA: Addison-Wesley.

3. Audzeyeva, A., \& Hudson, R. (2016). How to get the most from a business intelligence application during the post implementation phase? Deep structure transformation at a UK retail bank. European Journal of Information Systems, 25(1), 2946. https://doi.org/10.1057/ejis.2014.44

4. Aydiner, A. S., Tatoglu, E., Bayraktar, E., \& Zaim, S. (2019). Information system capabilities and firm performance: Opening the black box through decision-making performance and business-process 
performance.

IJIM,

$47(1)$,

168-182. https://doi.org/10.1016/j.ijinfomgt.2018.12.015

5. Bharadwaj, A. S. (2000). A resource-based perspective on information technology capability and firm performance: an empirical investigation. MIS quarterly, 24(1),169-196. https://doi.org/10.2307/3250983

6. Božič, K., \& Dimovski, V. (2019). Business intelligence and analytics for value creation: The role of absorptive capacity. International Journal of Information Management, 46(1), 93-103. https://doi.org/10.1016/j.ijinfomgt.2018.11.020

7. Bogdana, P. I., Felicia, A., \& Delia, B. (2009). The role of business intelligence in business performance management. Annals of Faculty of Economics, 4(1), 1025-1029.

8. Brynjolfsson, E., Hitt, L. M., \& Kim, H. H. (2011). Strength in Numbers: How does Data driven Decision making affect Firm Performance. Available at SSRN 1819486. https://doi.org/10.2139/ssrn.1819486

9. Carr, N. G. (2003). IT doesn't matter. Educause Review, 38(1), 24-38.

10. Chae, H. C., Koh, C. E., \& Prybutok, V. R. (2014). Information technology capability and firm performance: Contradictory findings and their possible causes. Mis Quarterly, 38(1), 305-326. https://doi.org/10.25300/misq/2014/38.1.14

11. Chin, W. W. (1998). Commentary: Issues and opinion on structural equation modeling. MIS Quartely, 22(1), vii-xvi.

12. Durcevic, S. (2018, September 13). Benefits of Business Intelligence \& Analytics Explained With Use-Cases. Retrieved October 31, 2019, from Datapine.com: https://www.datapine.com/blog/benefits-ofbusiness-intelligence-and-business-analytics/

13. Elbashir, M. Z., Collier, P. A., \& Davern, M. (2008). Measuring the effects of Business Intelligence systems: The relationship between business process and organizational performance. International Journal of Accounting Information Systems, 9(3), 135-153. https://doi.org/10.1016/j.accinf.2008.03.001

14. Fiol, M., \& Lyles, M. (1985). Organizational learning. Academy of Management Review, 10(4), 803-813.

15. Fink, L., Yogev, N., \& Even, A. (2017). Business intelligence and organizational learning: An empirical investigation of value creation processes. Information \& Management, 54(1), 3856. https://doi.org/10.1016/j.im.2016.03.009

16. Garson, G. D. (2016). Partial least squares: Regression and structural equation models. Asheboro: Statistical Associates Publishers. 
17. Gupta, M., \& George, J. F. (2016). Toward the development of a big data analytics capability. Information \& Management, 53(8), 10491064.

18. Hair Jr, J. F., Hult, G. T., Ringle, C., \& Sarstedt, M. (2014). A primer on partial least squares structural equation modeling (PLS-SEM). Los Angeles: SAGE Publication.

19. Hair Jr, J. F., Hult, G. T., Ringle, C., \& Sarstedt, M. (2017). A primer on partial least squares structural equation modeling (PLS-SEM). Thousand Oaks, California: SAGE Publications.

20. Henseler, J., Ringle, C. M., \& Sarstedt, M. (2015). A new criterion for assessing discriminant validity in variance-based structural equation modeling. Journal of the academy of marketing science, 43(1), 115135. https://doi.org/10.1007/s11747-014-0403-8

21. Henshen, D. (2008, May 9). Special Report: Business Intelligence Gets Smart. Retrieved January 19, 2020, from InformationWeek: https://www.informationweek.com /software/informationmanagement/special-report-business-intelligence-gets-smart/d/did/1071701

22. Işık, Ö., Jones, M. C., \& Sidorova, A. (2013). Business Intelligence success: The roles of BI capabilities and decision environments. Information \& Management, 50(1), 13-23. https://doi.org/10.1016/j.im.2012.12.001

23. Johnson, R. B., Onwuegbuzie, A. J., \& Turner, L. A. (2007). Toward a definition of mixed methods research. Journal of mixed methods research, 1(2), 112-133. https://doi.org/10.1177/1558689806298224

24. Kaplan, R., \& Norton, P. (1996). The Balanced Score Card: Translating Strategy into action. Boston MA: Harvard Business School Press .

25. Kangas, K. (1999). Competency \& capabilities-based competition and the role of information technology: the case of trading by a Finlandbased firm to Russia. Journal of Information Technology Case and Application Research, 1(2), 4-22.

26. Kenya National Bureau of Statistics, (2018). Economic survey. Retrieved January 20, 2019, from https://www.knbs.or.ke/?wpdmpro=economic-survey-2018

27. Kim, G., Shin, B., Kim, K. K., \& Lee, H. G. (2011). IT capabilities, process-oriented dynamic capabilities, and firm financial performance. Journal of the association for information systems, 12(7), 487-517. https://doi.org/10.17705/1jais.00270

28. Kinuthia, K. (2018). Firms that issued profit warning in 2018. Business Daily. Retrieved January 11, 2019, from companies/List--Firms-that- 
have-issued-profit-warning-this-year/4003102-487911414d53liz/index.html

29. Kohli, R., \& Grover, V. (2008). Business value of IT: An essay on expanding research directions to keep up with the times. Journal of the association for information systems, 9(1), 23-39. https://doi.org/10.17705/1jais.00147

30. Kulkarni, U. R., Robles-Flores, J. A., \& Popovič, A. (2017). Business intelligence capability: the effect of top management and the mediating roles of user participation and analytical decision making orientation. Journal of the Association for Information, 18(7), 516. doi:10.17705/1jais.0046

31. Larsen, K. R., \& Eargle, D. (2015). Retrieved March 13, 2019, from Theories Used in IS Research Wiki: https://is.theorizeit.org/wiki/Organizational_learning_theory

32. LaValle, S., Lesser, E., Shockley, R., Hopkins, M. S., \& Kruschwitz, N. (2011). Big data, analytics and path from insights to value. MIT sloan management review, 52(2), 21-32.

33. McGrath, R. G., MacMillan, I. C., \& Venkataraman, S. (1995). Defining and developing competence: A strategic process paradigm. Strategic management journal, 16(4), 251-275.

34. Melville, N., Kmerner, K., \& Gurbaxani, V. (2004). Review: Information Technology and Organizational Performance: An integrative model of IT business value. MIS quarterly, 28(2), 283-322. https://doi.org/10.2307/25148636

35. Mithas, S., Ramasubbu, N., \& Sambamurthy, V. (2011). How Information Management Capability Influences Firm Performance. MIS quarterly, 35(1), 237-256. https://doi.org/10.2307/23043496

36. Moore, S. (2017, February 17). Newsroom. Retrieved November 12, 2018, from Gartner Web site: https:// www.gartner.com/newsroom/id/3612617.

37. Olszak, C. M. (2014). Towards an Understanding Business Intelligence. A dynamic capability-based framework for Business Intelligence. Federated Conf. on IEEE 2(1), 1103-1110. https://doi.org/10.15439/2014f68

38. Peppard, J., \& Ward, J. (2004). Beyond strategic information systems: towards an IS capability. The Journal of Strategic Information Systems, 13(2), 167-194. https://doi.org/10.1016/j.jsis.2004.02.002

39. Ray, G., Muhanna, W. A., \& Barney, J. B. (2005). Information Technology and the Performance of the Customer Service: A Resource-Based Analysis. MIS Quarterly , 4(29), 625652. https://doi.org/10.2307/25148703 
40. Stevens, R. H. (2010). Managing human capital: How to use knowledge management to transfer knowledge in today's multigenerational workforce. International Business Research, 3(3), 77. https://doi.org/10.5539/ibr.v3n3p77

41. Trieu, V. H. (2017). Getting value from Business Intelligence systems: A review and research agenda. Decision Support Systems, 93(1), 111124. https://doi.org/10.1016/j.dss. 2016.09.019

42. Wade, M., \& Hulland, J. (2004). The resource-based view and information systems research: Review, extension, and suggestions for future research. MIS quarterly, 28(1), 107-142. https://doi.org/10.2307/25148626

43. Watson, H. J., \& Wixom, B. H. (2007). The current state of business intelligence. Computer, 40(9), 9699. https://doi.org/10.1109/mc.2007.331

44. Williams, S. (2016). Business intelligence strategy and big data analytics: A general management perspective. Cambridge: Morgan Kaufmann. https://doi.org/10.1016/c2015-0-01169-8

45. Xu, P., \& Kim, J. (2014). Achieving Dynamic Capabilities with Business Intelligence. In PACIS, (p. 330).

46. Yogev, N., Even, A., \& Fink, L. (2013). How Business Intelligence Creates Value. International Journal of Business Intelligence Research, 4(3), 16-31. https://doi.org/10.4018/ijbir.2013070102 